\title{
THE CONTRIBUTIONS OF GROUPWARE SYSTEMS TO ORGANIZATIONAL COMMUNICATION AND STRATEGIC MANAGEMENT IN COVID-19 EPIDEMIC PERIOD
}

\author{
DOI: 10.17261/Pressacademia.2020.1280 \\ RJBM- V.7-ISS.3-2020(5)-p.169-177

\section{Duygu Hidiroglu} \\ Mersin University, Recreation Management, Faculty of Tourism, 33330, Mersin, Turkey. \\ duyguhdr@mersin.edu.tr, ORCID: 0000-0003-2647-8750
}

Date Received: June 3, 2020

Date Accepted: September 5, 2020

To cite this document

Hidiroglu, D., (2020). The contribution of groupware systems to organizational communication and strategic management in Covid-19 epidemic period. Research Journal of Business and Management (RJBM), V.7(3), p.169-177.

Permanent link to this document: http://doi.org/10.17261/Pressacademia.2020.1280

Copyright: Published by PressAcademia and limited licensed re-use rights only.

\begin{abstract}
Purpose - The purpose of this study is discuss how Groupware systems integration and practices would affect the organizational communication and strategic management of business organizations in Covid-19 epidemic period.

Methodology - So what do people could do in these difficult conditions? Will people throw the ideas to garbage or they keep producing although they are into the trash? are the main discussion questions of this study.

Findings- Based on findings, by the process of wrestling the unpredictable environmental circumstances in Covid-19 period; it would be the most practical strategic decision for strategic managers and business leaders to integrate the Groupware systems to the business organizational structures and take advantage of Groupware systems in business operations as a communication tool.

Conclusion- The study concludes that many businesses in Covid-19 epidemic period should use Groupware systems since they provide many substantial contributions to business strategic management and ease the organizational communication.
\end{abstract}

Keywords: Strategic management, Covid-19 period, organizational communication, groupware systems, strategies in epidemic JEL Codes: M1, O3, L2

\section{INTRODUCTION}

Successful strategic management subjects to a problem itself, not to a solution. Managers could benefit from the real problem as an entrepreneurial opportunity by finding an innovative solution and start a new business to meet exact needs of society. Steve Blank, who is considered to be the Guru of Entrepreneurship and new startups, has a saying that "Get out of the building!". Most of people are just inside the building. To understand whether their ideas are correct or not; people need others' opinions. Different views could help people to discover whether the problem they have identified is really a problem that can benefit from as a good initiative. These days, due to the conditions of the Covid-19 epidemic make gathering others' ideas difficult to observe and implement. Because getting out of the building is very dangerous and not healthy so far.

Covid-19 period has damaged most of business activities and a variety of industries in many ways. Many developing businesses have been closed despite the fact that they were in the beginning stage of their lifecycle. Cities were empty, people were leaving their homes to migrate rural areas and they have preferred to wander away from shopping malls, markets and such crowded areas. Covid-19 period commonly has forced business people, entrepreneurs and employees to work from home by the necessity of social distance enforcement. However, the obligation of working from home might bring along several undesirable outcomes since many employees are not accustomed to work remotely. Most of managers have little idea about how they could decide future strategic plans and implement them to new working requirements and dealing with new abnormal working conditions constrains strategic managers. They are almost not even able to figure out and meet demands of their employees and working teams by afar. Most of strategic managers and decision makers in the organizations are emotionally unprepared to deal with such extraordinary circumstances. 
In the light of the reports published by the leading research institutes of the world such as The Gallup Wellbeing Index, Harvard Business Review, and The Self-employment Review including the evaluations of Covid-19 period, the researchers have reported that strategic managers, top level decision makers and entrepreneurs could not estimate which is the most appropriate needoriented business roadmap to follow regarding future business facilities and entrepreneurship activities after the epidemic. The decision making process in organizations would have influenced very unfavorably by the pandemic.

Today still the business people and strategic managers have no choice to get rid of the ambiguity and they have to deal with the uncertainty to survive. The best business approach would be deciding new strategic business plans and adapt them to the organizational practices and shortcomings of the former strategies to struggle tough economic conditions (Jeyaraj et al. 2006). To plan useful business strategies, managers have to exploit the technological and information systems on their business practices and the technological infrastructure of business organizations must have to be developed. By the process of wrestling the unpredictable environmental circumstances, it would be the most advantageous alternative for the strategic managers and the business leaders to integrate the Groupware systems to the organizational structures and take advantage of these systems in their organizational practices.

In the following section, the significant arguments compiled from the researches on the subject are discussed. After giving brief information about strategic management in Covid-19 epidemic period, how could strategic managers alter Covid-19 epidemic conditions to business growth opportunities will be discussed. Then, the differences in planning new strategies, establishing close relationship with employees and investing in home technologies to get effective business outcomes in Covid-19 period from same practices in pre-epidemic period will be debated. Further, the Groupware systems and the areas where these systems are used will be described. Lastly, developing new strategic business model by integrating Groupware systems, both the disadvantages and advantages of Groupware systems to organizational communication and strategic management in Covid-19 epidemic period will be discussed. Why Groupware systems are the appropriate technological systems for the business organizational communication and strategic management in the Covid-19 epidemic period, and the contribution of Groupware systems to strategic management and business organizations will be explained in the light of various insightful examples.

\section{LITERATURE REVIEW}

How could strategic managers alter covid-19 epidemic conditions to business growth opportunities? Strategic managers are forced to reshape the previous business strategies in this period. New strategic plans, new targets for employees, new funding requirements, a new supply chain management, new objectives for subordinates, a new organizational structure, new technological systems applications and implementations have been required in business organizations in recent Covid-19 period (Ågerfalk et al. 2020).

The new business scenarios and strategies forthcoming up with Covid-19 epidemic have been emerged by the volatility and inconstancy of demand for products and services which causes stress on many strategic managers. With respect to a survey conducted by Harvard Business School to measure the effects of Covid-19 on businesses and economies, $75 \%$ of the business owners who participated in the survey stated that they were highly deeply concerned about the unpredictable nugatory economic impact of the spread of the epidemic whole world.

If small and medium sized businesses redesign previous strategic business plans, they still have a chance to be succeed by switching these undesirably complex conditions to business opportunities. Since many of the strategic managers have altered working places as their homes, they feel undisturbed and free working environment allowing them to plan new feasible and applicable strategies; right.

\subsection{Planning New Strategies}

First, strategic managers should make sure that they have a strong motivation for how businesses can survive in difficult conditions. Managers should treat their working teams in early times in a day and strategic managers should set a plan against the negative expectations on their organizations regarding ideas everything will be getting worse in near future considering the business operations and future sales. Strategic managers should believe first that nothing will be get out of control and then they should make their employees believe same opinions and they should influence them in a positive manner.

For example, managers let their employees work from home will need to adapt a new technological infrastructure to lead their office workers and organizational operations in Covid-19 epidemic and provide them lack of technological devices and software in order to business duties and tasks being fulfilled from home (Wagner et al. 2019). On the other hand, managers have to rescheduled strategic plans and implement them to all marketing plans including existing markets and new markets to enter. 
Strategic managers also should take action to ensure the continuity of their business plans with their newly constructed organizational, technological and operational infrastructure.

\subsection{Establishing Close Relationship with Employees}

Strategic managers should provide effective communication with their employees whom allow them to work from home to avoid exposure to negative health consequences of the epidemic in their workplace. Even if employees already start to use some communication tools in their office by the epidemic, communication will gain a new dimension for managers when they switch from home as a working place. Physical appearance and online communication in the office environment is different from online communication in the home environment. Abuses are likely to occur in this new communication type, and managers may have some trust problems and even conflicts with their employees in spite of the fact that there is no shortage of many work-fromhome opportunities.

Strategic managers may have trouble communicating with their working teams in a meaningful and efficient way. Thus, to minimize such communication problems, they should find the video conference programs such as Zoom that best fits the existing remote technological system of the company and the software like Zoom videoconference program could meet communication needs and resolve some of reliance problems. Managers could not only contact with their employees but also they could use these programs to maintain the working environment where they can do brainstorm pioneering important ideas and useful insights. To illustrate, strategic managers could encourage the candidates to interview by video conferencing. Office-based faceto-face meetings allow strategic managers to execute the online version of meeting. Many of employees have the custom of ignoring notifications, claims, requests and orders when they are in the physical office are tend to continue these habits via online debates and conferences in the home offices. Accomplished strategic managers should remind these employees to stick to the business requests and should track the employees on the purpose of providing them to meet expectations quickly and complete their duties comprehensively. After all, these online tools are means of communication for managers during Covid-19 pandemic.

\subsection{Investing in Home Technologies to Get Effective Business Outcomes}

As a strategic manager, top executives make sure that homes of their employees are equipped with the latest technologies to help them work efficiently from home. Without these advanced technologies, the business practices, the productivity of organizations and strategic goals could be negatively affected. It is possible to face effectivity and efficiency troubles in business operations. Hence, strategic managers consider investing in the latest technologies for their employees to use their homes by not experiencing any connection errors (Mert, 2020).

There are very useful sophisticated technological tools managers could buy and integrate the business systems. For instance, strategic managers could benefit from the software up-to-date technologies such as Skyroam to radiate Wi-Fi signals from local data to distant networks. This will help the employees use the internet at the speed of office level without getting money out of their pocket. Similarly, managers could invest in some video conferencing programs such as Amazon Chime.

\section{CONCEPTUAL FRAMEWORK}

Groupware system which is a software that supports working teams' interactions and helps to improve some dynamics such as forming business calendars, scheduling business plans, and meeting on videoconferences (Mohamed et al. 2004). Applying knowledge management principles to enhance cross-functional team performance (Roseman and Greenberg, 1996). Journal of knowledge management. Groupware systems refer to online programs that afford assistance to business people working together collectively while the working places are located remotely from one place to another.

Groupware systems that enable business people in a real time collaboration which are called as a synchronous software. Groupware systems allows the employees to share of calendars, e-mail, information, business conferences online. Each organization member could observe and reach the dataset of other person having broadcasted. Groupware systems sometimes may be called as a collaborative software called as Computer-Supported Cooperative Work (CSCW) (Klein, 2012).

As mentioned Groupware systems have been generally classified in two groups: synchronous groupware and asynchronous groupware (Licea and Favela, 2000) regarding whether working team members collaborate in real time or not. Synchronous groupware supports group presentations online by the use of video calls or online chat (Sapsed et al. 2002). Synchronous groupware systems could assist online presentations from different working places at a same time, video calls with chat must have been at a different time at one working area before (Wang, 2008). 
On the other hand, asynchronous groupware systems require shared computers and software such as e-mail and the work flow of online business processes (Campbell, 2006). Meanwhile using same computer business people need to be in the same place but they have a chance to be online at different hours (Borges et al. 2001). Some high-tech software programs like online business workflows could give employees a chance to fulfill their personal tasks from different working places at different time durations (Wagner et al. 2019).

A couple of online applications of groupware systems subsume the programs Lotus Notes and Microsoft Exchange. These online systems could assure business people calendar sharing, e-mail sending, and the replicating working sheets and files via spread of online business network groupware system. As a result of online information sharing, all program users could reach the same data; in other words, the data becomes visible and accessible by network participants (Wise et al. 2013).

Moreover, online face-to-face conferences and business meetings could be performed by the programs CU-See Me and Microsoft NetMeeting. Lotus Notes and Domino Lotus Notes were the first full-featured data sharing groupware systems. These groupware system programs have been formed for the purpose of the use of customer care services and business operations like sales consultancy. These Groupware systems usage areas focus designing the concept of object stores in which data is gathered and analyzed by various replicated online server providers.

Domino advertisement systems like HTTP called as Hypertext Transfer Protocol services and online data storage services like Lotus Notes serve as an Internet application server which provides online systems security and keep the quality of online systems features such as encryption constant and sustainable (Markolf et al. 2018). Microsoft Exchange Server is similar to Notes and Domino (Tuma and Tuma, 2006). and it stores collaboration features and security information of working teams in an organizational online network (Robichaux, 1999). Novell GroupWise has boundaries restricted with Novell Directory Services which ensure a powerful online reviver to business workflows (Ying et al. 2014).

\section{DISCUSSION}

\subsection{Developing New Strategic Business Model by Integrating Groupware Systems}

Covid-19 epidemic has rendered many strategic business plans dysfunctional and outdated. Therefore, to cope with the new out of the common conditions; strategic managers require to implement new strategic plans and develop a practical business model. If managers do not have a strategic plan and business model to overcome adversity welded from Covid-19 pandemic, they have no chance to apply literal business practices (Seetharaman, 2020).

The managers could determine denouements that help business operations to keep up with critical changes by the help of Groupware systems applications. For instance, strategic managers could determine which of their business customers are by Groupware systems. The most crucial solution is empowering the organizational technological infrastructure in the Covid-19 epidemic period so that integrating Groupware systems applications to existing organizational information systems is the right action plan for the businesses should implement right now (Liu et al.2020). Strategic managers could generate new marketing strategies by the use of Groupware systems with an ease to keep these plans functional since Groupware systems applications could ensure strategic managers a facility of close supervision. Some of the suppliers could not be responding to demands of businesses, strategic managers could identify other alternative suppliers during this period. Strategic managers should get the business priorities right and they need to temporarily postpone some non-priority transactions until the getting over these troublesome days.

\subsection{The Disadvantages of Groupware Systems to Organizational Communication and Strategic Management in Covid-19 Epidemic Period}

Groupware systems have lots of advantages, but the systems have several disadvantages in business organizations. Groupware systems may bring impersonality, technological problems, lack of social cues or may slow to develop new business connections and may extend the process of completing business tasks (Bergiel et al. 2008).

The disadvantage linked with impersonality is about the behavioral science. People could not get face to face communication which limits mimics and body expressions. This may result in loss of reliability among working team members responsible for business projects and thus the group members may hesitate to share their individual ideas (Wang and Reani, 2017). This impersonality issue may also lead to miscommunication and misunderstandings due to the lack of body and facial expressions. Misinterpretation of information sharing is commonplace when communication is done via information systems (Alvarez et al. 2016). 
The disadvantage of technological problems may have arisen from either the multitude or lack of Groupware systems' features. The number of applications of groupware systems may cause complexity for program users whom are inexperienced of doing mistakes while interpreting the dataset. Furthermore, Groupware systems may trigger the invasion of personal privacy because of the lack of unreal social indications (Gilson et al. 2015).

Another disadvantage is related with the cost of Groupware systems applications and the affordability of program users. In Covid19 epidemic period, there has been an economic crisis whole of the world and many economic restrictions of small to medium sized businesses have been faced while budgeting their business operations. Thus many businesses have perceived that they could not afford to invest in Groupware systems integration to their information systems and despite the fact that Groupware systems applications have been required for the success of organizational practices, strategic managers could not decide to pay for it. Some of the practices of Groupware systems are training programs, technical support, operating, and server and networking hardware and these practices cost too much compared to the budget and the capital level of many companies (Rienties et al. 2012).

The other disadvantage of Groupware systems may be the network speed and the reliability of data sharing. Businesses having outdated information systems may observe many failures of systems due to the compatibility of the systems. However, program users of Groupware systems would not face such problems since Groupware systems have strict data share policy which protects the rights of customers without any legacy gaps and missing.

Lots of disadvantages of Groupware systems applications have been based on the fact that these information systems could only be successful if a critical mass of program users have been preferred to apply the systems. However, Groupware systems users usually have low level of education on the business community concerning systems. This low level education leads a doubt of strategic managers that investing in Groupware systems is a right decision regarding the capability of organization members to effectively apply these systems to their duties and business tasks (Luppicini, 2007). Having a videophone is useless if a person is the only one who has it (Wagner and Thompson, 2017). Another concern that contributes to Groupware systems is the notion of interoperability and the lack of compatibility of online applications. If strategic managers have decided to invest in Groupware systems that they would have to sustain that business people or the employees, they desire to connect via these systems must have the compatible form of technologic devices and software as well (Hamilton, 2020).

\subsection{The Advantages of Groupware Systems to Organizational Communication and Strategic Management in Covid- 19 Epidemic Period}

Groupware systems applications make easier for people to do what task they have to fulfill easily as expected by almost all strategic managers in Covid-19 epidemic period (Stuerzlinger et al. 2006). The success and effectiveness of Groupware systems on business operations are closely linked with several success factors. For instance, in multicultural firms due to cultural differences Groupware systems could change in practice to support collaboration and this ability of adaptability to certain changes makes sure employees feel secured and supported by the organizations since groupware systems only work completely when employees feel secured in organizational structures (Suadamara, 2011).

Furthermore, Groupware systems could promote connect business people by making employees feel a part of the projects of organizations and the systems allow employees to start communication from the beginning of their attendance in organizations and keeping strong communication up till they decide to leave their job (Kuruppuarachchi, 2009). This advantage of Groupware systems is very helpful for achieving success in strategic management and meeting the new normal organizational requirements in Covid-19 epidemic period.

Supporting and coordinating the data sharing and communication network among employees are the main goals of information systems (Lee and Choi, 2003). Yet, information systems are not in charge of dictating and controlling them (Lee et al. 2012). Groupware systems must provide some contributions to program users. For example, these systems have to have some online education packages which help program users to learn how to apply Groupware systems applications to their business practices (Fransen et al. 2011). Besides, Groupware systems section each stage in accordance with the next rollout warning, this warning makes the application more comprehensible and practical in order to address unknowing business program users.

There is one motivational illustration of an organization using groupware systems in Covid-19 epidemic period. This organization really attaches significance to its rivalries and needs of its customers. The firm had not utilized the information systems as efficiently as it has done in recent epidemic period. Thus the company could administrate the analysis of internal operations such as technological capabilities, the weaknesses of technological infrastructure, and the requirements of technological systems (Chorfi et al. 2020). 
The chief information officer ( $\mathrm{ClO}$ ) has quickly improved and reformed the firm's internal use of information technology systems by the Covid-19 epidemic period. The most important task of $\mathrm{ClO}$ has been the formation of firm-wide information systems standards in order to compete with the competitors in business environment having uncertain conditions. While reviewing communication software and focusing on gaining competitive advantage among the rivals, ClO has notices the Notes groupware systems (Liu et al., 2020). ClO has introduced later that Groupware system is a breakthrough technological system; because this online system has the potential to form a revolution in how business members both inside and outside of the organization communicate simultaneously and Groupware systems could coordinate business activities and information sharing by the regard of inspecting security issues. Ere long, $\mathrm{ClO}$ has acquired a site license to apply and integrate Notes to the information systems of the organization.

$\mathrm{CIO}$ has applied Notes program greatly within various parts of the organizational operations. ClO has set the business principals to the lower level managers both at national meetings via Groupware systems and meetings at local offices through information systems. During these meetings $\mathrm{CIO}$ has promoted company vision of how Notes could help to lead company expertise and to ensure the interoperability of business facilities (Penichet, 2008).

In Covid-19 epidemic period, based on companies' interests and purposes the requests to information systems especially Groupware systems have improved and the authorization of technological infrastructure in almost all companies has empowered rapidly throughout the information systems of firms in spite of the fact that the widespread use of Groupware systems within the home offices had advanced slowly before Covid-19 epidemic period (Pan and Zhang, 2020). Groupware systems where the e-mail access had been commonly adopted into information systems, the application of Groupware systems in data sharing processes and the integration of Groupware systems into business operations and strategic management systems, had been panned out of well at home offices remote control systems in Covid-19 epidemic period. According to moderate level field studies about Groupware systems integration to remote information systems, the researchers argue that at least two organizational goals such as cognitive and structural goals of the organizations have impacted by the adaptability of employees and executive managers to and the ability to understand the mechanism of these information systems.

Briefly, Groupware systems have lots of advantages for businesses and strategic management decision especially in Covid-19 epidemic crisis although several disadvantages (Verma and Gustafsson, 2020). If users of Groupware systems could decrease the social pressure, these systems become efficient for organizational practices due to saving process time and making processes more flexible. Groupware systems also may reduce travel expenses and information sharing cost. Further, these systems provide to facilitate faster, easier, more persuasive and more clear social network, enable telecommuting, make forming project teams with common interests easy where gathering many people by face-to-face at the same time at a same place and help to solve problems of working teams fast (De Araujo, 2018).

All in all, Groupware systems could increase efficiency of business operations. Each group member responsible for a certain project could access to all of information relevant to business tasks. Abundant work could be eliminated by Groupware systems, less time is required for searching data, and so group members have a chance to spare more time to work on required tasks. In addition, Groupware systems could arise the creativity. With an open communication, each member of working groups could share new ideas and diversified insights which improve the innovativeness of the project as a whole (Van Slyke et al. 2002). Lastly, Groupware systems could regulate common schedules, manage e-mails with ease, maintain bulletin boards, hold real-time network meetings, share files collectively with the calendars and make database and spreadsheets access practical and applicable.

\section{CONCLUSION}

In Covid-19 epidemic period, strategic managers require the services of freelancers to overcome the difficulties of tracking and working from home. These freelancers are professionals with significant experiences about information systems allowing business people to work from home remotely and provide the desired business results. Fortunately, there are many experienced freelancers in information systems sectors and businesses today.

If strategic managers decide to invest in Groupware systems such as Notes information systems, online applications and data sharing systems etc. they may be considering reducing the other business costs, since Groupware systems integration is highly expensive especially for small and medium sized companies. One of the leading Groupware systems companies, has hosted thousands of designers from all over the world and has organized a design contest to enter leading innovative markets (Van Slyke et al. 2004). After all this company is able to quickly access and convince many new Groupware systems users to buy their information systems and integrate their existing business organizations at an affordable pay in exchange for a low-cost award to the winner. 
Those who work in information systems industries where the Covid-19 epidemic is deeply negatively affected often have transferable technological skills that could add value to the companies taking advantages of Groupware systems. Many strategic managers may have broader skills and experiences in different industries but; it is now time to learn and apply more on information systems technologies (Abdous and Yoshimura, 2010). The strategic managers who could demonstrate superior energy and have a motivation to learn more about Groupware systems could plan and manage accomplished business strategies in Covid19 epidemic period (Giesbers et al. 2014).

In summary, the study concludes that many businesses in Covid-19 epidemic period should use Groupware systems since the systems provide many substantial contributions to business strategic management although these systems have several disadvantages being eliminated. The only concern that strategic managers should notice is the organizations have to have properly educated employees and systems users on the procedures of Groupware systems to get maximum benefit from these systems in business operations. In order to obtain the maximum efficiency level from Groupware systems, employers need to take full advantage of all the systems features and tools that Groupware systems offer.

\section{REFERENCES}

Abdous, M. H., \& Yoshimura, M. (2010). Learner outcomes and satisfaction: A comparison of live video-streamed instruction, satellite broadcast instruction, and face-to-face instruction. Computers \& education, 55(2), 733-741.

Ågerfalk, P. J., Conboy, K., \& Myers, M. D. (2020). Information systems in the age of pandemics: COVID-19 and beyond. European Journal of Information Systems, 1-5.

Alvarez, I., Zamanillo, I., \& Cilleruelo, E. (2016). Have information technologies evolved towards accommodation of knowledge management needs in Basque SMEs?. Technology in Society, 46, 126-131.

Bergiel, B. J., Bergiel, E. B., \& Balsmeier, P. W. (2008). Nature of virtual teams: a summary of their advantages and disadvantages. Management research news.

Borges, M. R., Pino, J. A., \& Valle, C. (2001). Interfaces for groupware. In CHI'01 Extended Abstracts on Human Factors in Computing Systems (pp. 47-48).

Campbell, H. M. (2006). The role of organizational knowledge management strategies in the quest for business intelligence. In 2006 IEEE International Engineering Management Conference (pp. 231-236). IEEE.

Chorfi, A., Hedjazi, D., Aouag, S., \& Boubiche, D. (2020). Problem-based collaborative learning groupware to improve computer programming skills. Behaviour \& Information Technology, 1-20.

De Araujo, D. H. M., de Carvalho, E. A., da Motta, C. L. R., da Silva Borges, M. R., Gomes, J. O., \& de Carvalho, P. V. R. (2018). Social networks applied to Zika and H1N1 epidemics: a systematic review. In Congress of the International Ergonomics Association (pp. 679-692). Springer, Cham.

Fransen, J., Kirschner, P. A., \& Erkens, G. (2011). Mediating team effectiveness in the context of collaborative learning: The importance of team and task awareness. Computers in human Behavior, 27(3), 1103-1113.

Jeyaraj, A., Rottman, J. W., \& Lacity, M. C. (2006). A review of the predictors, linkages, and biases in IT innovation adoption research. Journal of information technology, 21(1), 1-23.

Giesbers, B., Rienties, B., Tempelaar, D., \& Gijselaers, W. (2014). A dynamic analysis of the interplay between asynchronous and synchronous communication in online learning: The impact of motivation. Journal of Computer Assisted Learning, 30(1), 30-50.

Gilson, L. L., Maynard, M. T., Jones Young, N. C., Vartiainen, M., \& Hakonen, M. (2015). Virtual teams research: 10 years, 10 themes, and 10 opportunities. Journal of management, 41(5), 1313-1337.

Hamilton, J. (2020). The Strategic Change Matrix and Business Sustainability across COVID-19. Sustainability, $12(15), 6026$.

Klein, M. (2012). Enabling large-scale deliberation using attention-mediation metrics. Computer Supported Cooperative Work (CSCW), 21(4-5), 449-473.

Kuruppuarachchi, P. R. (2009). Virtual team concepts in projects: a case study. Project Management Journal, 40(2), 19-33.

Lee, H., \& Choi, B. (2003). Knowledge management enablers, processes, and organizational performance: An integrative view and empirical examination. Journal of management information systems, 20(1), 179-228.

Lee, S., Kim, B. G., \& Kim, H. (2012). An integrated view of knowledge management for performance. Journal of Knowledge management.

Licea, G., \& Favela, J. (2000). An extensible platform for the development of synchronous groupware. Information and Software technology, 42(6), 389-406. 
Liu, Y., Qafzezi, E., Ampririt, P., Ohara, S., \& Barolli, L. (2020). FBPCQS-Fuzzy-Based Peer Coordination Quality Systems for P2P Networks: Implementation and Performance Evaluation. International Journal of Mobile Computing and Multimedia Communications (IJMCMC), 11(3), 2237.

Luppicini, R. (2007). Review of computer mediated communication research for education. Instructional science, 35(2), 141-185.

Markolf, S. A., Chester, M. V., Eisenberg, D. A., Iwaniec, D. M., Davidson, C. I., Zimmerman, R., ... \& Chang, H. (2018). Interdependent infrastructure as linked social, ecological, and technological systems (SETSs) to address lock-in and enhance resilience. Earth's Future, 6(12), $1638-1659$.

Mert, G. (2020). “Kurumların Stratejik Yönetim Süreçlerinde Dijitalleşmenin Rolü”, Journal of Social, Humanities and Administrative Sciences, 6(22): 41-58.

Mohamed, M., Stankosky, M., \& Murray, A. (2004). Applying knowledge management principles to enhance cross-functional team performance. Journal of knowledge management.

Pan, S. L., \& Zhang, S. (2020). From fighting COVID-19 pandemic to tackling sustainable development goals: An opportunity for responsible information systems research. International Journal of Information Management, 102196.

Penichet, V. M. R., Lozano, M. D., Gallud, J. A., Tesoriero, R., Rodríguez, M. L., Garrido, J. L., ... \& Hurtado, M. V. (2008). Extending and Supporting Featured User Interface Models for the Development of Groupware Applications. J. UCS, 14(19), 3053-3070.

Rienties, B., Giesbers, B., Tempelaar, D., Lygo-Baker, S., Segers, M., \& Gijselaers, W. (2012). The role of scaffolding and motivation in CSCL. Computers \& Education, 59(3), 893-906.

Robichaux, P. (1999). Managing Microsoft Exchange Server. John Wiley \& Sons.CA, USA. First Edition. ISBN:1565925459. (1).3-63.

Roseman, M., \& Greenberg, S. (1996). TeamRooms: Groupware for shared electronic spaces. In Conference Companion on Human Factors in Computing Systems (pp. 275-276).

Sapsed, J., Bessant, J., Partington, D., Tranfield, D., \& Young, M. (2002). Teamworking and knowledge management: a review of converging themes. International journal of management reviews, 4(1), 71-85.

Seetharaman, P. (2020). Business models shifts: Impact of Covid-19. International Journal of Information Management, 54, 102173.

Stuerzlinger, W., Zaman, L., Pavlovych, A., \& Oh, J. Y. (2006). The design and realization of CoViD: a system for collaborative virtual 3D design. Virtual Reality, 10(2), 135-147.

Suadamara, R. (2011). Integrating culture in designing groupware applications as contribution to intercultural collaboration technology (Doctoral dissertation, Duisburg, Essen, 2011).

Tuma, W. B., \& Tuma, G. B. (2006). U.S. Patent No. 7,155,633. Washington, DC: U.S. Patent and Trademark Office.

Van Slyke, C., Belanger, F., \& Comunale, C. L. (2004). Factors influencing the adoption of web-based shopping: the impact of trust. ACM SIGMIS Database: the DATABASE for Advances in Information Systems, 35(2), 32-49.

Van Slyke, C., Lou, H., \& Day, J. (2002). The impact of perceived innovation characteristics on intention to use groupware. Information Resources Management Journal (IRMJ), 15(1), 1-12.

Verma, S., \& Gustafsson, A. (2020). Investigating the emerging COVID-19 research trends in the field of business and management: A bibliometric analysis approach. Journal of Business Research.

Wagner, T. A., \& Thompson, J. P. (2017). U.S. Patent No. 9,785,476. Washington, DC: U.S. Patent and Trademark Office.

Wagner, T. A., Brooker, M. J., \& Nair, A. (2019). U.S. Patent No. 10,282,229. Washington, DC: U.S. Patent and Trademark Office.

Wang, W. (2008). Powermeeting: gwt-based synchronous groupware. In Proceedings of the nineteenth ACM conference on Hypertext and hypermedia (pp. 251-252)

Wang, W., \& Reani, M. (2017). The rise of mobile computing for Group Decision Support Systems: A comparative evaluation of mobile and desktop. International Journal of Human-Computer Studies, 104, 16-35.

Wise, A. F., Speer, J., Marbouti, F., \& Hsiao, Y. T. (2013). Broadening the notion of participation in online discussions: examining patterns in learners' online listening behaviors. Instructional Science, 41(2), 323-343.

Ying, S., Wu, G., Wang, Q., \& Shen, D. (2014). Hierarchical unbiased graph shrinkage (HUGS): a novel groupwise registration for large data set. Neurolmage, 84, 626-638. 